\title{
Substrate and product analogues as human $O$-GlcNAc transferase inhibitors
}

\author{
Helge C. Dorfmueller • Vladimir S. Borodkin • \\ David E. Blair · Shalini Pathak • Iva Navratilova • \\ Daan M. F. van Aalten
}

Received: 21 May 2010/Accepted: 1 July 2010/Published online: 17 July 2010

(C) The Author(s) 2010. This article is published with open access at Springerlink.com

\begin{abstract}
Protein glycosylation on serine/threonine residues with $\mathrm{N}$-acetylglucosamine $(\mathrm{O}$-GlcNAc) is a dynamic, inducible and abundant post-translational modification. It is thought to regulate many cellular processes and there are examples of interplay between $O$-GlcNAc and protein phosphorylation. In metazoa, a single, highly conserved and essential gene encodes the $O$-GlcNAc transferase (OGT) that transfers GlcNAc onto substrate proteins using UDP-GlcNAc as the sugar donor. Specific inhibitors of human OGT would be useful tools to probe the role of this post-translational modification in regulating processes in the living cell. Here, we describe the synthesis of novel UDP-GlcNAc/UDP analogues and evaluate their inhibitory properties and structural binding modes in vitro alongside alloxan, a previously reported weak OGT inhibitor. While the novel analogues are not active on living cells, they inhibit the enzyme in the micromolar range and together with the structural data provide useful templates for further optimisation.
\end{abstract}

Keywords $O$-GlcNAc $\cdot$ Post-translational modification · Inhibitor $\cdot$ Signalling $\cdot$ Crystal structure

Electronic supplementary material The online version of this article (doi:10.1007/s00726-010-0688-y) contains supplementary material, which is available to authorized users.

H. C. Dorfmueller · V. S. Borodkin - D. E. Blair · S. Pathak ·

D. M. F. van Aalten ( $\square)$

Division of Molecular Microbiology, College of Life Sciences, University of Dundee, Dundee DD1 5EH, Scotland, UK

e-mail: dmfvanaalten@dundee.ac.uk

D. E. Blair · I. Navratilova

Division of Biological Chemistry and Drug Discovery,

College of Life Sciences, University of Dundee,

Dundee DD1 5EH, Scotland, UK

\section{Introduction}

Reversible post-translational modification of many cytoplasmic and nuclear proteins in eukaryotic cells by glycosylation of serine and threonine residues with $\beta$-linked $N$-acetylglucosamine ( $O$-GlcNAc) has been shown to regulate cellular processes as diverse as transcription, translation, insulin sensitivity, protein trafficking and degradation (Torres and Hart 1984; Zachara and Hart 2004; Love and Hanover 2005; Hart et al 2007). Only two enzymes are responsible for the dynamic cycling of $O$-GlcNAc. The $O$-GlcNAc transferase (OGT) transfers GlcNAc, using UDP-GlcNAc as the sugar donor, via an inverting mechanism involving as yet unidentified active site residues. The $O$-GlcNAc hydrolase (OGA) cleaves the glycosidic bond, thus reversing the modification. Dysregulation of $O$-GlcNAc is thought to play a role in human pathogenesis, such as cancer (Chou and Hart 2001; Liu et al. 2002; Donadio et al. 2008), Alzheimer's (Griffith and Schmitz 1995; Yao and Coleman 1998; Liu et al. 2004; Wells and Hart 2003; Dias and Hart 2007) and diabetes (McClain et al. 2002; Copeland et al. 2008). Hundreds of cytoplasmic and nucleoplasmic proteins have been shown to be $O$-GlcNAc modified, although the precise glycosylation sites and functional implications have been determined for only a few of these. Interestingly, examples of crosstalk between protein $O$-GlcNAcylation and phosphorylation have been recently reported, with the $O$-GlcNAcylation site being either identical or adjacent to protein phosphorylation sites (Yang et al. 2006). However, the precise molecular mechanisms by which OGT and OGA recognise and act on hundreds of proteins, thereby regulating cellular signalling cascades, remain to be discovered (Hurtado-Guerrero et al. 2008). The OGA enzyme has been characterised in humans, rat, Drosophila and C. elegans (Kelly and Hart 1989; Dong and Hart 
1994; Gao et al. 2001; Comtesse et al. 2001; Forsythe et al. 2006). The OGA reaction mechanism has been elucidated and structural insights have been obtained recently from bacterial OGA homologues (Macauley et al. 2005; Rao et al. 2006; Dennis et al. 2006; Ficko-Blean et al. 2009). A wealth of chemical biological tools exist to raise intracellular $O$-GlcNAc levels in living cells by inhibition of $O$-GlcNAcase. Until recently the only inhibitors of hOGA were the aspecific compounds PUGNAc (Haltiwanger et al. 1998) and streptozotocin (STZ) (Liu et al. 2000). Lately, several new compounds have been described that selectively and potently inhibit human OGA (Macauley et al. 2005; Dennis et al. 2006; Dorfmueller et al. 2006; Dorfmueller et al. 2009; Stubbs et al. 2006; Yuzwa et al. 2008). These chemical tools are currently enabling studies towards the role of $O-G l c N A c$ in a range of signal transduction pathways, although it is becoming clear that certain cell types are remarkably tolerant of inhibitor-induced hyper- $O$-GlcNAcylation.

OGT was discovered first in rat (Haltiwanger et al. 1992), subsequently in Arabidopsis thaliana (Jacobsen et al. 1996), humans (Kreppel et al. 1997), C. elegans (Lubas et al. 1997) and more recently in Giardia and Cryptosporidium parvum (Banerjee et al. 2009). The gene that encodes for human OGT (hOGT) resides on the $\mathrm{X}$ chromosome and is essential for mammalian development (Shafi et al. 2000). hOGT is ubiquitously expressed, however, at particularly high levels in T cells, B cells and macrophages, whereas lower expression levels are found in pancreatic $\beta$-cells and the central nervous system (Hanover et al. 2009).

The first insights into OGT structure have recently been obtained from an apparent bacterial OGT orthologue from Xanthomonas campestris (XcOGT) (Clarke et al. 2008; Martinez-Fleites et al. 2008). Structural complexes with UDP and an UDP-GlcNAc phosphonate analogue revealed features of the active site and three distinct domains: (1) multiple tetratricopeptide repeats (TPRs), (2) a linker region and (3) the catalytic (glycosyltransferase activity) domain, belonging to the GT41 family in the CAZy database (Coutinho et al. 2003). The active site is located between the two lobes of the GT41 domain. While hOGT mutants informed by the structural complexes (Clarke et al. 2008; Martinez-Fleites et al. 2008) have helped to identify several inactive mutants, however, the precise catalytic mechanism of OGT yet remains to be discovered.

The $O$-GlcNAc modification is a dynamic modification, and thus potent and selective hOGT inhibitors would be beneficial to investigate the role of $O$-GlcNAc modifications in signalling pathways. The first hOGT inhibitor reported was alloxan, an uracil analogue that is presumed to inhibit hOGT by binding to the uracil binding pocket or alternatively has been proposed to act through a covalent modification of cysteine residues (Konrad et al. 2002).
Alloxan, as a small chemical compound, is unlikely to inhibit hOGT specifically in vivo (Zachara et al. 2004). Furthermore, alloxan is a chemically unstable compound with a half-life time of $1.5 \mathrm{~min}$ at physiological $\mathrm{pH}$ (Lenzen and Munday 1991). Although alloxan inhibits hOGT with an $\mathrm{IC}_{50}$ of $100 \mu \mathrm{M}$ (Konrad et al. 2002), it is required at millimolar concentrations to decrease cellular levels of $O$-GlcNAcylation (Liu et al. 2005, 2006, 2007; Noach et al. 2007; Kang et al. 2008). Recently, three novel hOGT inhibitors were identified by high-throughput screening (HTS) (Gross et al. 2005), although the original report did not show that these compounds were able to decrease global cellular $O$-GlcNAc levels by inhibition of hOGT in living cells. A very recent report showed that one of these inhibitors identified by HTS reduces $O$-GlcNAc levels in MCF-10A-ErbB2 breast cancer cells when applied at $500 \mu \mathrm{M}$ (Caldwell et al. 2010).

Here, we report the design and evaluation of a novel glycosyl thiophosphate analogue of UDP-GlcNAc (UDP$S$-GlcNAc) and an $\alpha, \beta$-methylene bisphosphonate analogue of UDP ( $C$-UDP) as hOGT inhibitors. We have determined inhibition constants of these compounds against hOGT and used X-ray crystallography to demonstrate that the uridine pyrophosphate moiety (or its mimic) occupies the nucleotide sugar binding site in both cases. We have also determined the binding mode of alloxan, a widely used (unspecific) hOGT inhibitor. Together, these compounds and associated data form the basis for the future rational design of more potent substrate analogue OGT inhibitors.

\section{Materials and methods}

Protein production and purification

$X c$ OGT wild-type (WT), mutant D471A-XcOGT and hOGT (26-end) were expressed and purified as described previously (Clarke et al. 2008). The proteins were concentrated to $10 \mathrm{mg} / \mathrm{ml}(X c \mathrm{OGT}, \mathrm{D} 471 \mathrm{~A}-\mathrm{XcOGT})$ and $10 \mu \mathrm{M}$ (hOGT), respectively.

Surface plasmon resonance experiments

The molecular interaction between WT/mutant D471A$X c$ OGT and nucleotide analogues were studied by surface plasmon resonance (SPR), using a BIAcore T100 instrument (BiaCore, Uppsala, Sweden). WT and the D471A mutantXcOGT were immobilised using standard amine-coupling chemistry in buffer consisting of $10 \mathrm{mM}$ HEPES (pH 7.4) and $150 \mathrm{mM} \mathrm{NaCl}$. The sensor chip surface was activated at $25^{\circ} \mathrm{C}$ with a 7 min injection of a $1: 1$ mixture of EDC and NHS. Protein was injected at $0.2 \mathrm{mg} / \mathrm{ml}$ in acetate buffer $\mathrm{pH}$ 5.5 at a flow rate of $10 \mu \mathrm{l} / \mathrm{min}$ for $1 \mathrm{~min}$ to achieve suitable 
density of approximately 5000 RU. Finally, 1 M ethanolamine- $\mathrm{HCl}$ was injected for $7 \mathrm{~min}$ to deactivate the surface. One flow cell was used as a reference to subtract nonspecific binding, drift and bulk refractive index. All experiments were performed in $25 \mathrm{mM}$ Tris- $\mathrm{HCl}(\mathrm{pH} 7.5)$, and $150 \mathrm{mM}$ $\mathrm{NaCl}$ at $25^{\circ} \mathrm{C}$. Compounds were diluted in the running buffer at a maximum concentration of $1 \mathrm{mM}$ and then threefold diluted to a concentration series ranging from $1 \mathrm{mM}$ to $457 \mathrm{nM}$. Association was measured for $30 \mathrm{~s}$ and dissociation for $60 \mathrm{~s}$ at a $30 \mu \mathrm{l} / \mathrm{min}$ flow rate. Injections were carried out in duplicate. Blank injections of running buffer were used during the experiment to control the drift of baseline. As the experimental run time exceeded $15 \mathrm{~h}$, control injections of UDP at $100 \mu \mathrm{M}$ were included within the run at every eighth sample injection to detect possible changes of activity of immobilised proteins on the surface. Data processing and affinity analysis were performed using Scrubber 2 software (BioLogic Software). Data were corrected for blank reference surface to subtract non-specific binding and for blank buffer injections to subtract possible drift in sensorgrams. Binding of compounds was measured using SPR to WT-XcOGT and mutant D417A. No decrease of response for control injections of UDP $(100 \mu \mathrm{M})$ was observed during the experimental run, suggesting that the binding capacity of immobilised protein remained the same (data not shown). Data were fitted using equilibrium affinity analysis. Since most of the compound affinities were in millimolar range exceeding the highest concentration of injected compound, the maximum binding capacity ( $\left.\mathrm{R}_{\mathrm{MAX}}\right)$ could not be reached. Therefore, to calculate $\mathrm{R}_{\mathrm{MAX}}$, UDP was used as a control. The affinity of UDP was calculated as $110 \mu \mathrm{M}$ and reached maximum binding capacity of approximately $36 \mathrm{RU}$. The responses for the rest of the compounds were normalised according to their molecular weights and fitted using equilibrium fit with $\mathrm{R}_{\text {MAX }}$ previously calculated for UDP. In this way, binding affinities could be estimated for compounds as weak as $30 \mathrm{mM}$.

\section{Determination of the $X c$ OGT complex crystal structures}

Purified WT-XcOGT protein was crystallised essentially as described previously (Clarke et al. 2008). Vapour diffusion crystallisation experiments were performed by mixing $1 \mu \mathrm{l}$ of $X c \mathrm{OGT}$ protein $(10 \mathrm{mg} / \mathrm{ml})$ and $1 \mu \mathrm{l}$ of mother liquor (0.1 M CHES, pH 9.5 and $25 \%$ polyethylene glycol 3350 ). To obtain the $X c$ OGT-UDP-S-GlcNAc/C-UDP and alloxan complexes, crystals were soaked by addition of $1 \mu \mathrm{l}$ of $20 \mathrm{mM}$ UDP- $S$-GlcNAc/ $C$-UDP dissolved in mother liquor or solid alloxan. The crystals were cryoprotected by immersion in mother liquor with increased (40\%) polyethylene glycol 3350 concentration. Synchrotron diffraction data were collected and processed using the HKL suite (Pape and Schneider 2004). Refinement of the ligand complexes was initiated from the native $X c$ OGT-UDPGlcNAc phosphonate structure (2JLB) (Clarke et al. 2008). Further model building with COOT (Emsley and Cowtan 2004) and refinement with REFMAC (Murshudov et al. 1997) yielded the final models with statistics shown in Table 3. In all three complexes, defined $\left|F_{\mathrm{o}}\right|-\left|F_{\mathrm{c}}\right|, \phi_{\text {calc }}$ electron density for the compounds was apparent from the early stages of refinement. Compound models were built and refined using coordinates and topologies generated by PRODRG (Schuettelkopf and van Aalten 2004). Comparison of the $X c$ OGT-UDP-S-GlcNAc and $X c$ OGT-alloxan complexes with previously described $X c \mathrm{OGT}$ structures (Clarke et al. 2008; Martinez-Fleites et al. 2008) shows that there is more disorder in the N-terminal TPR domains, which were only partially built. This is reflected in higher B-factors (Table 3).

\section{Inhibition measurements}

hOGT assays were carried out at room temperature (RT) in 384-well white optiplates (Perkin Elmer). Each assay was performed in a $20 \mu \mathrm{l}$ reaction volume containing $50 \mathrm{mM}$ Tris buffer, $\mathrm{pH} 7.5,2 \mathrm{mM}$ dithiothreitol (DTT), $3 \mathrm{mM}$ $\mathrm{MgCl}_{2}, 0.05 \mathrm{mg} / \mathrm{ml}$ BSA (Thermo), $0.125 \mu \mathrm{M}\left[{ }^{3} \mathrm{H}\right] \mathrm{UDP}-$ GlcNAc (0.048 $\mathrm{Ci} \mathrm{mmol}^{-1}$ ) (Sigma/ARC), $1 \mu \mathrm{M}$ biotinylated DEBtide (Blair et al. manuscript submitted) (GlycoBioChem), $50 \mathrm{nM}$ hOGT and various concentrations of test compounds. Test compounds were placed in the columns 1 and 13 of a 384-well polypropylene plate and then serially diluted in $100 \%$ DMSO through half log increments using a JANUS 8-channel Varispan automated workstation (PerkinElmer) to give the compound source plate $(100 \times$ final assay concentration). From this, $0.25 \mu \mathrm{l}$ of the compounds were transferred to all wells using a Cartesian Hummingbird (Genomics Solution) before $10 \mu \mathrm{l}$ of either enzyme/peptide mix or peptide alone (control) was added to the assay plates. The reaction was initiated with $10 \mu \mathrm{l}$ of UDP-GlcNAc and stopped after $150 \mathrm{~min}$ with $40 \mu \mathrm{l}$ of a stop solution containing $0.2 \mathrm{M}$ phosphoric acid, $\mathrm{pH} 4.0$ and $1.5 \mathrm{M} \mathrm{MgCl}_{2}$ and $2.5 \mathrm{mg} / \mathrm{ml}$ PVT SPA beads (GE Healthcare). All reaction mixture additions were carried out using a Thermo Scientific WellMate (Matrix). Plates were sealed and read on a TopCount NXT Microplate Scintillation and Luminescence Counter (Perkin Elmer). Dose-response curves were prepared and analysed using GraFit (Leatherbarrow 2001) (Fig. 1b).

\section{Synthesis of UDP-S-GlcNAc}

Compound 2 (Fig. 1c): To a solution of 2-acetamido-2deoxy-3,4,6-tri- $O, O, O$-acetyl-1-thio- $\alpha$-D-glucopyranose (Knapp and Myers 2001) (0.393 g, 1.08 mmol) and bis(9Hfluoren-9-ylmethyl)-diisopropylamidophosphite (Bialy and 
(A)
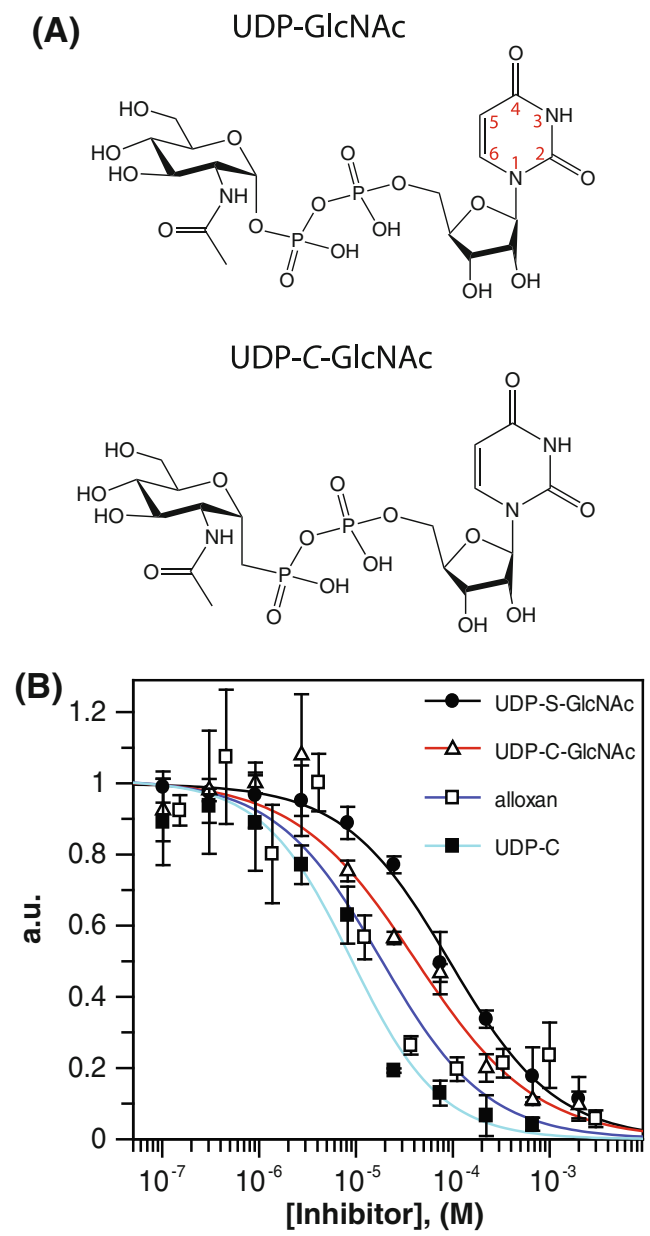

Fig. 1 Design, synthesis and inhibitory properties of hOGT substrate/ product analogues. a Chemical structures of UDP-GlcNAc, the substrate of hOGT, the substrate analogues UDP- $C$-GlcNAc and UDP- $S$-GlcNAc, the hOGT product UDP and the analogue $C$-UDP and alloxan. The atoms in the uracil moiety are numbered. Alloxan ring atoms are numbered according to the uracil numbering system. b Dose-response curves of the inhibitors with hOGT. The transfer of GlcNAc from UDP-GlcNAc onto a peptide [DEBtide (Blair et al. manuscript submitted)] by hOGT was assayed in presence of increasing concentrations of UDP-S-GlcNAc, UDP-C-GlcNAc,

Waldmann 2004) (0.846 g, $1.6 \mathrm{mmol})$ in $\mathrm{MeCN}(4 \mathrm{ml})$, a stock $0.45 \mathrm{M}$ solution of $1 H$-tetrazole $(7.1 \mathrm{ml}, 3.2 \mathrm{mmol})$ was added at RT. After $30 \mathrm{~min}$, the reaction mixture was cooled down to $-40^{\circ} \mathrm{C}$ and a solution of dimethyldioxirane $(19 \mathrm{ml} ; 0.1 \mathrm{M}, 1.9 \mathrm{mmol})$ was added in one portion. The reaction mixture was further stirred for 30 min while the temperature was allowed to reach $-20^{\circ} \mathrm{C}$. The reaction was removed from the cooling bath and concentrated. The residue was dissolved in DCM and washed with water, dried and concentrated. The residue was purified by flash chromatography in Tol- $\mathrm{Me}_{2} \mathrm{CO} 5-30 \%$ to give $0.344 \mathrm{~g}$ of the target product $2(0.43 \mathrm{mmol} ; 40 \%)$ (supplementary materials).
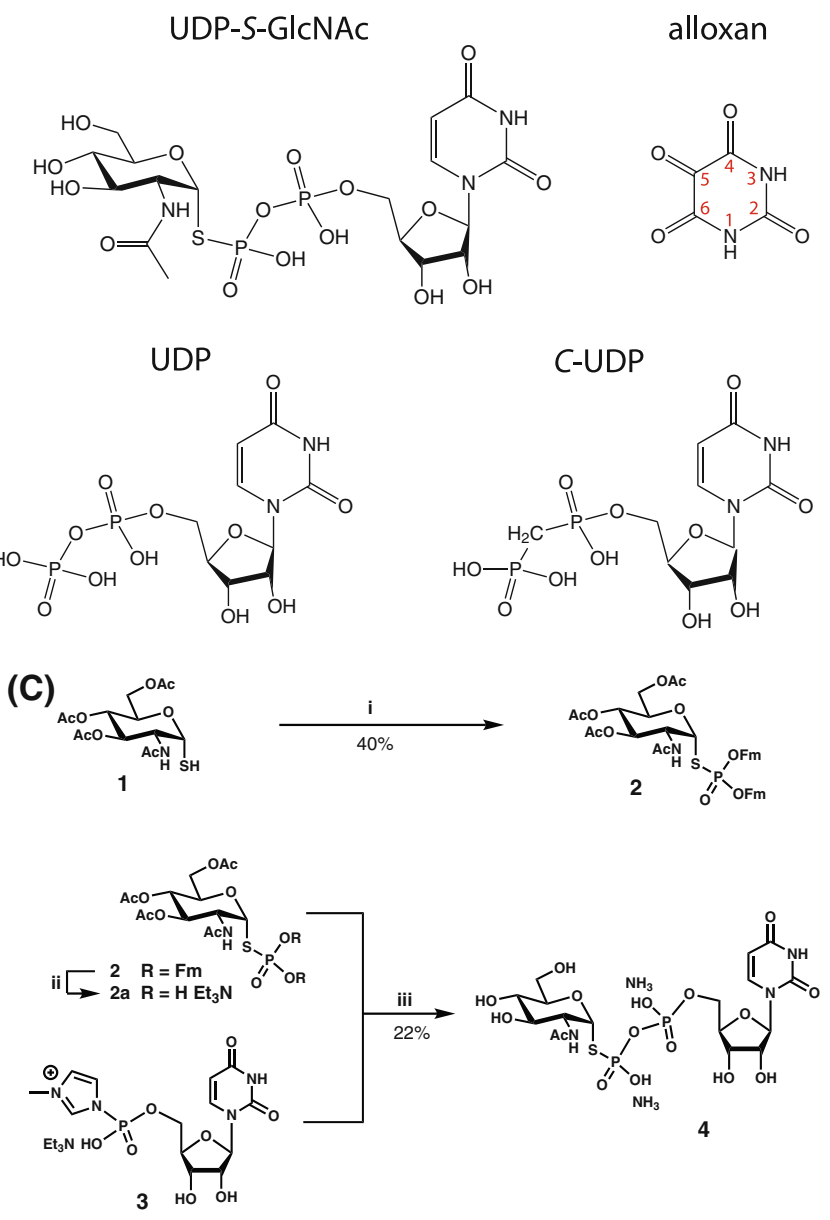

alloxan and $C$-UDP. The remaining activity is plotted against the inhibitor concentration. Data were fitted using the standard $\mathrm{IC}_{50}$ equation in the GraFit program (Leatherbarrow 2001). c Reagents and conditions for UDP-S-GlcNAc synthesis: (i) Bis(9H-fluoren-9ylmethyl)-diisopropylamidophosphite, $1 \mathrm{H}$-tetrazole, MeCN, RT, $30 \mathrm{~min}$; then dimethyldioxirane, $-40^{\circ} \mathrm{C}$ to $-20^{\circ} \mathrm{C}, 30 \mathrm{~min}$; (ii) DCM: ${ }_{3} \mathrm{~N}$ (4:1), RT, 24 h; (iii) (a) $\mathbf{2 a}+\mathbf{3}, \mathrm{MeCN}, \mathrm{RT}, 16 \mathrm{~h}$; (b) $\mathrm{MeOH}: \mathrm{H}_{2} \mathrm{O}: \mathrm{Et}_{3} \mathrm{~N}$ (5:2:1), RT, $16 \mathrm{~h}$; followed by size exclusion chromatography

Compound 4 (Fig. 1c): A solution of the protected thiophosphate $2(0.12 \mathrm{~g}, 0.15 \mathrm{mmol})$ in a mixture of DCM $(3 \mathrm{ml})$ and triethylamine $(0.75 \mathrm{ml})$ was kept at $\mathrm{RT}$ for $24 \mathrm{~h}$. The reaction mixture was concentrated and dried in vacuum to give crude glycosyl thiophosphate (2a), (supplementary materials).

To a stirred slurry of uridine $5^{\prime}$-monophosphate bis-triethylammonium salt $(0.076 \mathrm{~g}, 0.144 \mathrm{mmol})$ in a mixture of anhydrous $\mathrm{MeCN}(0.6 \mathrm{ml}), N, N$-dimethylaniline $(0.070 \mathrm{ml}$, $0.56 \mathrm{mmol})$ and $\mathrm{Et}_{3} \mathrm{~N}(0.04 \mathrm{ml}, 0.288 \mathrm{mmol})$, a solution of trifluoroacetic anhydride $(0.12 \mathrm{ml}, 0.864 \mathrm{mmol})$ in $\mathrm{MeCN}(0.2 \mathrm{ml})$ was added via capillary at $0^{\circ} \mathrm{C}$. The reaction mixture was stirred for a few minutes at RT, while clear 
yellowish solution was formed and concentrated to remove excess of trifluoroacetic anhydride. The yellow oily residue was re-dissolved in $\mathrm{MeCN}(0.5 \mathrm{ml})$ and cooled to $0^{\circ} \mathrm{C}$. A solution of $N$-methylimidazole $(0.057 \mathrm{ml}, 0.72 \mathrm{mmol})$ and $\mathrm{Et}_{3} \mathrm{~N}(0.12 \mathrm{ml}, 0.864 \mathrm{mmol})$ in anhydrous $\mathrm{MeCN}(0.2 \mathrm{ml})$ was then added to the above solution via capillary. The reaction mixture was further stirred for $15 \mathrm{~min}$ at RT. The prepared solution of UMP- $N$-methylimidazolide (3) was added via capillary to a flask containing a solution of the crude product $2 \mathbf{a}$ in $\mathrm{MeCN}(0.8 \mathrm{ml})$ at $0^{\circ} \mathrm{C}$. The resulting turbid yellow solution was further stirred overnight at RT. The reaction was quenched by addition of cold $\mathrm{Et}_{3} \mathrm{NHHCO}_{3}$ buffer $(1 \mathrm{ml})$ and stirred for $20 \mathrm{~min}$. The reaction was concentrated; the residue was dissolved in a mixture of $\mathrm{MeOH}: \mathrm{H}_{2} \mathrm{O}: \mathrm{Et}_{3} \mathrm{~N}(5: 2: 1,8 \mathrm{ml})$ and kept at $\mathrm{RT}$ for $16 \mathrm{~h}$. The reaction mixture was concentrated, diluted with water, and extracted with DCM. The layers were separated and the aqueous phase was additionally extracted with DCM. The aqueous layer was concentrated to give yellowish oily residue. This was purified by size exclusion chromatography (Bio-Gel P2 fine; column $2.6 \times 100 \mathrm{~cm}$; flow rate $0.4 \mathrm{ml} /$ min; elution with $0.25 \mathrm{M} \mathrm{NH} \mathrm{NHCO}_{3}$ ). The fractions containing the product were pooled and evaporated. The residue was re-dissolved in water and freeze dried to give $0.0216 \mathrm{~g}(0.012 \mathrm{mmol}, 22 \%)$ of the target product 4 (95\% purity by ${ }^{1} \mathrm{H}$ NMR) as fluffy white solid (supplementary materials).

UDP- $C$-GlcNAc and $C$-UDP analogues were synthesised as described previously (Clarke et al. 2008; Borodkin et al., manuscript submitted). Alloxan was purchased from Sigma-Aldrich.

\section{Results and discussion}

Design and synthesis of substrate/product analogues as potential OGT inhibitors

In the absence of potent, cell permeable OGT inhibitors we decided to explore substrate analogues as potential inhibitor scaffolds. We aimed to investigate UDP-GlcNAc analogues as hOGT inhibitors, in which the glycosidic oxygen would be replaced with non-hydrolysible isosteric linkages conferring stability towards enzymatic and chemical hydrolysis. Recent studies have described the synthesis and evaluation of a UDP-GlcNAc glycosyl C-phosphonate analogue (UDP$C$-GlcNAc, Fig. 1a) against $O$-GlcNAc transferases of different origin (Clarke et al. 2008; Chang et al. 2006). Interestingly, UDP- $C$-GlcNAc did not show any inhibitory activity against hOGT (Hajduch et al. 2008), potentially indicating an essential role of the glycosidic oxygen atom in substrate binding. It is possible that the lack of hydrogen bonds between the isosteric, albeit non-isopolar, methylene group of the glycosyl C-phosphonate explains why UDP- $C$ GlcNAc is a weak hOGT inhibitor.

In a search for novel non-hydrolysable UDP-GlcNAc congeners with enhanced biological activity profiles, a thioglycosyl (thiophosphate) analogue of UDP-GlcNAc (UDP-S-GlcNAc, Fig. 1a) was envisaged as a possible target. Replacement of the glycosyl oxygen with the sulphur atom would give rise to an analogue, which despite not being isosteric (van der Waals radius of sulphur is $1.85 \AA$ compared to $1.44 \AA$ for oxygen) would still bear more resemblance to the natural $O$-linked substrate than the glycosyl C-phosphonate analogue. This non-hydrolysable substrate analogue might further reveal insight into the binding mode of UDP-GlcNAc, since the previously

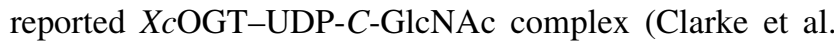
2008) revealed a substrate binding site which is not fully compatible with catalysis of larger nucleotide-sugar analogues that were reported previously (Gross et al. 2005; Laughlin and Bertozzi 2009).

No thiophosphate analogues of nucleotide diphosphate sugars have so far been synthesised, except for an anomeric sulphur analogue of CMP-Neu5Ac (Cohen and Halcomb 2000). This unique compound was found to be surprisingly hydrolytically stable compared to the natural $O$-linked substrate and two orders of magnitude poorer substrate for $\alpha$-2,3-sialyl transferase than the natural $O$-linked substrate (Cohen and Halcomb 2000). No evidence of a perceptible inhibition of the sialyl transferase activity with this compound was reported.

We envisioned that the UDP-S-GlcNAc (Fig. 1a) could be prepared by coupling of suitably protected GlcNAc glycosyl thiophosphate and activated 5'-uridine monophosphate by analogy with the common practice of pyrophosphate bond construction in the chemical synthesis of nucleoside diphosphate sugars. Initially, GlcNAc diallylthiophosphate (not shown) was prepared from the $\alpha$-configured GlcNAc glycosyl thiol 1 (Fig. 1c) as a potential precursor of GlcNAc glycosyl thiophosphate according to the published procedure (Knapp and Myers 2001). However, all attempts to liberate thiophosphate functionality by removing allyl groups from this compound using tetrakis (triphenylphosphine) palladium catalyst in the presence of various allyl cation scavengers were utterly unsuccessful, leading predominantly to the formation of dephosphorylated products. Seeking for an alternative solution, we suggested that change of the thiophosphate protecting groups to 9-fluorenylmethyl would allow the deprotection in mild anhydrous conditions. Thus, the glycosyl thiol $\mathbf{1}$ (Fig. 1c) was S-phosphitylated with bis(9H-fluoren-9ylmethyl)-diisopropylamidophosphite (Bialy and Waldmann 2004) followed by oxidation with dimethyldioxirane to give the GlcNAc bis-9-fluorenylmethyl glycosyl thiophosphate 2 (Fig. 1c) in acceptable yield $\left({ }^{31} \mathrm{P} ; \delta\right.$ 23.36). 
Removal of the protecting groups by treatment with $\mathrm{Et}_{3} \mathrm{~N}$ in DCM for $24 \mathrm{~h}$ produced the requisite glycosyl thiophosphate 2a (Fig. 1c) as judged by ${ }^{31} \mathrm{P}$ NMR spectrum, showing the presence of the single phosphorous containing product $\left({ }^{31} \mathrm{P} ; \delta 13.06\right)$. The crude glycosyl thiophosphate was then reacted with UMP-N-methylimidazolide 3 (Fig. 1c; Marlow and Kiessling 2001) to furnish the target molecule in moderate yield after deprotection and purification by gel filtration chromatography. Formation of the pyrophosphate bond was evident from the presence of typical pair of doublets $\delta 5.10$ and $-11.97\left(J_{P, P^{\prime}}=29 \mathrm{~Hz}\right)$ in the ${ }^{31} \mathrm{P}$ spectrum of compound 4 .

To investigate the inhibition of UDP-GlcNAc and UDP analogues, kinetic studies were carried out using recombinant hOGT protein. A synthetic peptide (DEBtide) was used as the acceptor substrate. The incorporation of $\left[{ }^{3} \mathrm{H}\right]$ GlcNAc from $\left[{ }^{3} \mathrm{H}\right]-\mathrm{UDP}-\mathrm{GlcNAc}$ was monitored using a newly developed radioactive assay (Blair et al. manuscript submitted). The $K_{\mathrm{m}}$ for UDP-GlcNAc was determined to be $1 \mu \mathrm{M}$, in agreement to the $K_{\mathrm{m}}$ determined previously (Haltiwanger et al. 1992). In our hands, hOGT displays product inhibition with UDP $\left(\mathrm{IC}_{50}\right.$ of $1.8 \mu \mathrm{M}$, Fig. 1a). We therefore also decided to explore the inhibition profile of a non-hydrolysible $\alpha, \beta$-methylene bisphosphonate analogue with the pyrophosphate oxygen replaced by a methylene group ( $C$-UDP).

Synthesis of $C$-UDP was performed using published procedures (Borodkin et al., manuscript submitted).

\section{UDP-S-GlcNAc-a sub-millimolar inhibitor of hOGT} and substrate binding probe

Using the glycosyltransferase assay with a model acceptor peptide, UDP-S-GlcNAc appears to inhibit hOGT with an $\mathrm{IC}_{50}$ of $93 \mu \mathrm{M}$ (Fig. 1b; Table 1), similar to the previously described weak hOGT inhibitor UDP-C-GlcNAc (Clarke et al. 2008; Hajduch et al. 2008) $\left(\mathrm{IC}_{50}=41 \mu \mathrm{M}\right.$, Fig. 1b;

Table 1 Inhibition data of the hOGT substrate/product analogues

\begin{tabular}{llc}
\hline Compound & $\mathrm{IC}_{50}[\mu \mathrm{M}]^{\mathrm{a}}$ & $\mathrm{BEI}^{\mathrm{b}}$ \\
\hline UDP & $1.8 \pm 1.0$ & 15 \\
$C$-UDP & $9.0 \pm 1.0$ & 13 \\
UDP-C-GlcNAc & $41 \pm 7$ & 7 \\
UDP-S-GlcNAc & $93 \pm 15$ & 7 \\
Alloxan & $18 \pm 1$ & 34 \\
\hline
\end{tabular}

a The dose-response experiments were performed with a UDPGlcNAc concentration tenfold below the $K_{\mathrm{m}}$

${ }^{\mathrm{b}}$ Binding efficiency index (Abad-Zapatero and Metz 2005), $\mathrm{BEI}=-\log \left(K_{\mathrm{i}}\right) / M$, with $\mathrm{M}$ being the mass in $\mathrm{kDa}$ and $K_{\mathrm{i}}$ is derived from $\mathrm{IC}_{50}$ data using the Cheng and Prusoff equation with $[\mathrm{S}]=125 \mathrm{nM}$ and $K_{\mathrm{m}}=1 \mu \mathrm{M}$. Cheng-Prusoff equation: $K_{\mathrm{i}}=\mathrm{IC}_{50} /$ $1+\left([\mathrm{S}] / K_{\mathrm{m}}\right)$
Table 1). Human OGT has so far resisted expression and purification to levels required for structural studies and biophysical measurement of ligand affinity. To further study the binding mode of the novel UDP-GlcNAc analogues, we therefore used the apparent hOGT homologue from Xanthomonas campestris pv. campestris (XcOGT) for which structural data and protein crystals suitable for soaking studies are available (Clarke et al. 2008; MartinezFleites et al. 2008). SPR experiments with recombinant and purified $X c$ OGT protein revealed that UDP has a binding affinity $\left(K_{\mathrm{d}}\right)$ of $112 \mu \mathrm{M}$ for $X c \mathrm{OGT}$ (Table 2), which should be compared to inhibition with $\mathrm{IC}_{50}=1.8 \mu \mathrm{M}$ of hOGT activity (Tables 1, 2). The micromolar hOGT inhibitors UDP-S-GlcNAc and UDP- $C$-GlcNAc both bind $X c$ OGT weakly, with a $K_{\mathrm{d}}>1 \mathrm{mM}$ (Table 2). UDP-GlcNAc itself binds to $X c$ OGT weakly with a $K_{\mathrm{d}}$ of approximately $15 \mathrm{mM}$ (Table 2). We next investigated whether UDP-S-GlcNAc is a substrate for hOGT or XcOGT. Kinetic experiments using recombinant hOGT/XcOGT and protein acceptor substrates in conjunction with a general $O$-GlcNAc antibody did not show any evidence for $O$-GlcNAcylation. Furthermore, a colorimetric assay with the thio-reactive reagent DTNB [5,5'-dithio-bis(2-nitrobenzoic acid)], and a fluorescent assay with $N$-(1-pyrene) maleimide did not shown any hydrolysis of UDP-SGlcNAc by hOGT or XcOGT.

To investigate the binding mode of the UDP-S-GlcNAc substrate analogue, $X c$ OGT protein crystals were soaked with the compound. Collection of synchrotron diffraction data and subsequent refinement yielded a final model with statistics shown in Table 3. UDP-S-GlcNAc binds in the active site of $X c$ OGT (Fig. 2a). The uracil moiety occupies a pocket formed by Lys441 to His444, whilst stacking with the side chain of Tyr447 (Fig. 2a). The uracil moiety is involved in a total of three hydrogen bonds with the protein, with the backbone of Leu442/Pro443 and the His444 side chain (Fig. 2a). The ribose moiety of UDP-S-GlcNAc makes a hydrogen bond with Asp471 (Fig. 2), a side chain that is conserved in OGTs from organisms across the evolutionary spectrum. Recent studies reported that a mutant of the equivalent position in hOGT (Asp925) is no longer able to $O$-GlcNAcylate an acceptor substrate (Clarke et al. 2008; Martinez-Fleites et al. 2008). SPR measurements show that the D471A-XcOGT mutant no longer binds UDP-GlcNAc (Table 2).

Surprisingly, a structural comparison with the previously described UDP-C-GlcNAc complex (Clarke et al. 2008) shows that while the uridine moiety occupies a similar position in both complexes (maximum atom shift $=0.8 \AA$ ), the sugar and phosphate moieties occupy different binding sites (Fig. 2a). The UDP-S-GlcNAc phosphate mimics occupy a groove, interacting with the side chains of Lys388 (Lys842 in hOGT) and Asn385 
Table 2 Dissociation constant $\left(K_{\mathrm{d}}\right)$ of compounds for $X c$ OGT-WT from SPR experiments

\begin{tabular}{lll}
\hline Compound & \multicolumn{2}{l}{$K_{\mathrm{d}}(\mathrm{mM})$} \\
\cline { 2 - 3 } & WT-XcOGT & D471A-XcOGT \\
\hline UDP & $0.110 \pm 0.001$ & n.b. \\
$C$-UDP & $0.530 \pm 0.006$ & n.b. \\
UDP-GlcNAc & $15.1 \pm 0.5$ & n.b. \\
UDP-S-GlcNAc & $>1$ & $>1$ \\
UDP- $C$-GlcNAc & $>1$ & $>1$ \\
Alloxan & $>1$ & n.d. \\
\hline
\end{tabular}

n.b. $=$ no binding

n.d. $=$ not determined

[Gln839 in hOGT, mutation of which inactivates the enzyme (Clarke et al. 2008; Martinez-Fleites et al. 2008)]. The sugar moiety occupies a position above the pyrophosphate, hydrogen bonding with His 218 and Arg137 (Fig. 2a). In contrast to the previously described UDP- $C$ GlcNAc- $X c \mathrm{OGT}$ crystallographic complex (Clarke et al. 2008), this binding mode is compatible with the reported tolerance of hOGT for larger substitutions on the $N$-acetyl group (Gross et al. 2005; Laughlin and Bertozzi 2009), and also exposes the $\beta$-face of the anomeric carbon for nucleophilic attack (Fig. 2a). Loss of activity in hOGT His558 mutants (His218 in $\mathrm{XcOGT}_{c}$ ) has been proposed to reflect a role as a general base in the reaction mechanism
(Martinez-Fleites et al. 2008), which would be incompatible with the UDP-S-GlcNAc conformation described here (Fig. 2a). Similarly, Cys917 (Tyr463 in XcOGT) has been proposed to be the catalytic base to activate the peptide substrate, but is not in proximity to the GlcNAc anomeric carbon in the UDP-S-GlcNAc complex. Interestingly, the complex shows that the hydroxyl group of Tyr387 is positioned within $4.5 \AA$ from the anomeric carbon. This Tyr387 is conserved amongst $X c$ OGT and hOGT (Fig. 2a; Clarke et al. 2008) and is in close proximity to Lys388, which could prime the tyrosine to act as a base to activate the acceptor substrate. However, the identity of the hOGT catalytic machinery remains to be firmly established.

The $\alpha, \beta$-methylene bisphosphonate UDP is a micromolar hOGT inhibitor

We have found that the $\alpha, \beta$-methylene bisphosphonate UDP analogue ( $C$-UDP) appears to inhibit hOGT with an $\mathrm{IC}_{50}$ of $9 \mu \mathrm{M}$ (Table 1; Fig. 1b). The binding affinity of $C$-UDP to $X c$ OGT was investigated by SPR experiments, revealing a $K_{\mathrm{d}}$ of $530 \mu \mathrm{M}$ (Table 2). This binding constant is approximately fivefold weaker than for UDP, but in agreement with the ranking observed for hOGT inhibition (Tables 1, 2).

We determined the crystal structure of the XcOGT$C$-UDP complex to investigate the molecular basis of the weaker hOGT inhibition and $X c$ OGT binding compared
Table 3 Details of data collection and structure refinement for UDP-S-GlcNAc, $C$-UDP and alloxan bound to $X_{c} \mathrm{OGT}$

Values within brackets are for the highest resolution shell. All measured data were included in structure refinement

\begin{tabular}{|c|c|c|c|}
\hline & $\begin{array}{l}X c \text { OGT-UDP-S- } \\
\text { GlcNAc }\end{array}$ & $X c \mathrm{OGT}-C$-UDP & $X c$ OGT-alloxan \\
\hline Space group & $\mathrm{P} 2{ }_{1} 2_{1} 2_{1}$ & $\mathrm{P} 2{ }_{1} 2_{1} 2_{1}$ & $\mathrm{P} 2{ }_{1} 2_{1} 2_{1}$ \\
\hline \multirow[t]{3}{*}{ Unit cell $(\AA)$} & $\mathrm{a}=83.7$ & $\mathrm{a}=84.3$ & $\mathrm{a}=83.5$ \\
\hline & $\mathrm{b}=100.0$ & $\mathrm{~b}=95.0$ & $\mathrm{~b}=100.0$ \\
\hline & $\mathrm{c}=155.5$ & $\mathrm{c}=157.7$ & $\mathrm{c}=157.2$ \\
\hline Resolution range $(\AA)$ & $\begin{array}{l}30.00-2.60 \\
(2.69-2.60)\end{array}$ & $\begin{array}{l}30.00-2.40 \\
\quad(2.46-2.40)\end{array}$ & $\begin{array}{l}30.00-2.55 \\
\quad(2.64-2.55)\end{array}$ \\
\hline \# Observed reflections & 181,565 & 170,621 & 171,199 \\
\hline \# Unique reflections & $37,400(3,453)$ & $47,424(2,347)$ & $42,658(4,136)$ \\
\hline Redundancy & $4.9(4.9)$ & $3.6(3.2)$ & $4.0(3.9)$ \\
\hline $\mathrm{I} / \sigma \mathrm{I}$ & $32.5(2.9)$ & $13.6(2.15)$ & $16.3(2.1)$ \\
\hline Completeness $(\%)$ & $91.7(86.4)$ & $92.9(70.1)$ & $97.8(96.7)$ \\
\hline$R_{\text {merge }}$ & $0.061(0.691)$ & $0.067(0.543)$ & $0.048(0.438)$ \\
\hline$R, R_{\text {free }}$ & $23.9,27.7$ & $24.4,30.4$ & $25.4,29.7$ \\
\hline \multicolumn{4}{|l|}{ RMSD from ideal geometry } \\
\hline Bonds $(\AA)$ & 0.01 & 0.01 & 0.02 \\
\hline Angles $\left({ }^{\circ}\right)$ & 1.5 & 1.4 & 1.5 \\
\hline $\begin{array}{l}\text { B-factor RMSD (backbone bonds) } \\
<\mathrm{B}>\left(\AA^{2}\right)\end{array}$ & 0.5 & 0.5 & 0.5 \\
\hline Protein & 73.4 & 45.0 & 75.6 \\
\hline Ligand & 78.7 & 38.2 & 71.7 \\
\hline Solvent & 66.6 & 48.1 & 72.1 \\
\hline
\end{tabular}


(A)

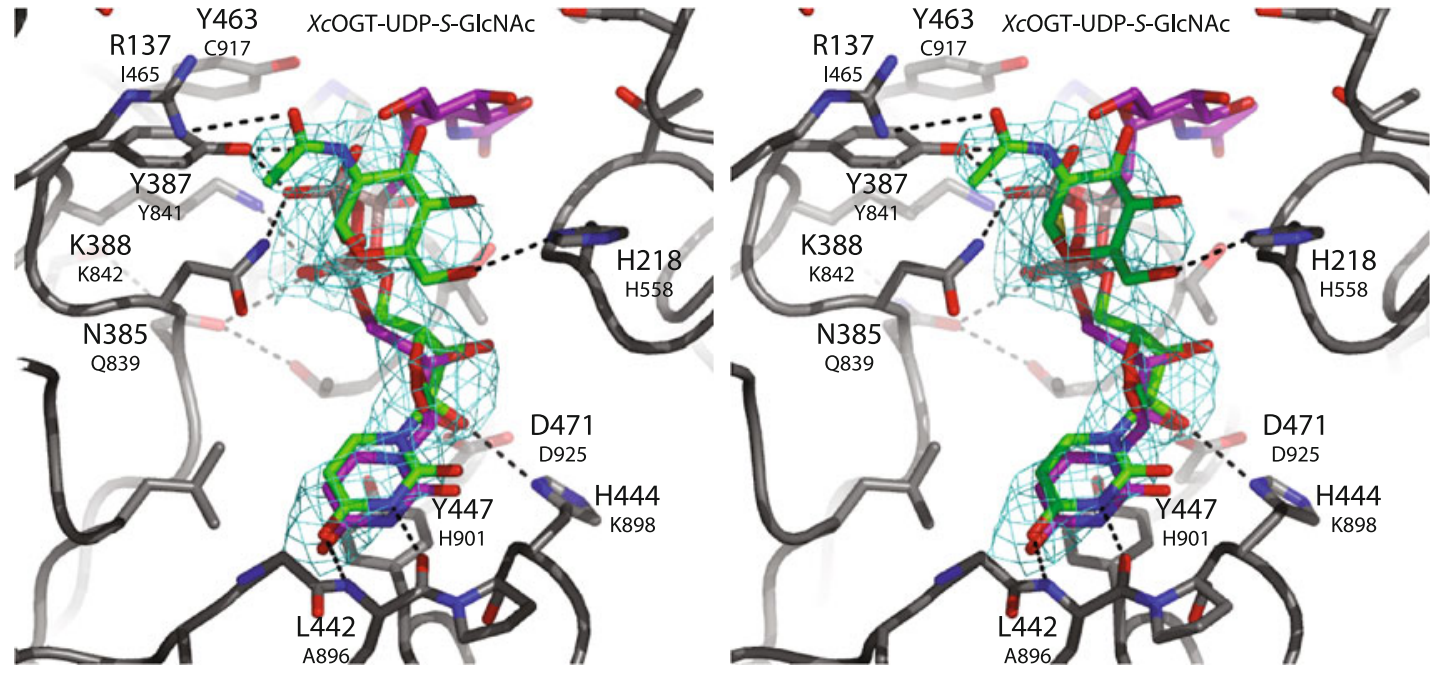

(B)

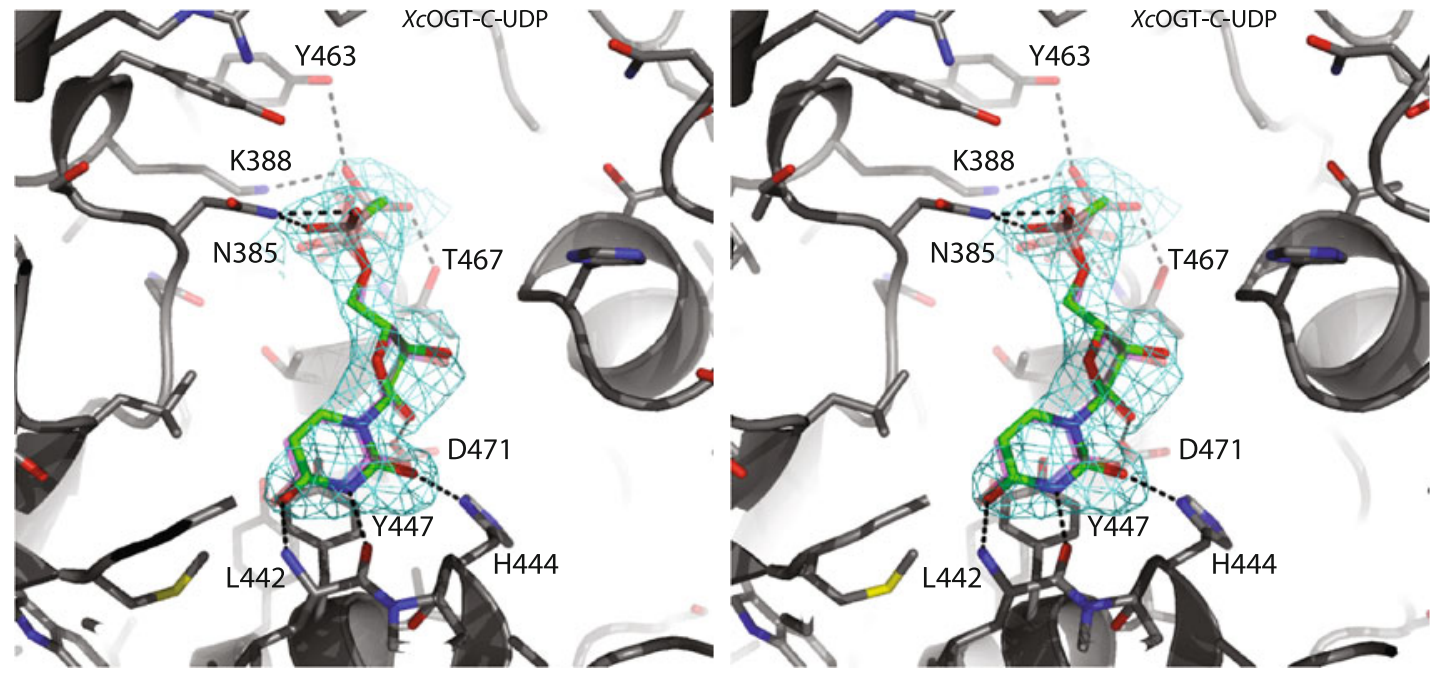

(C) -
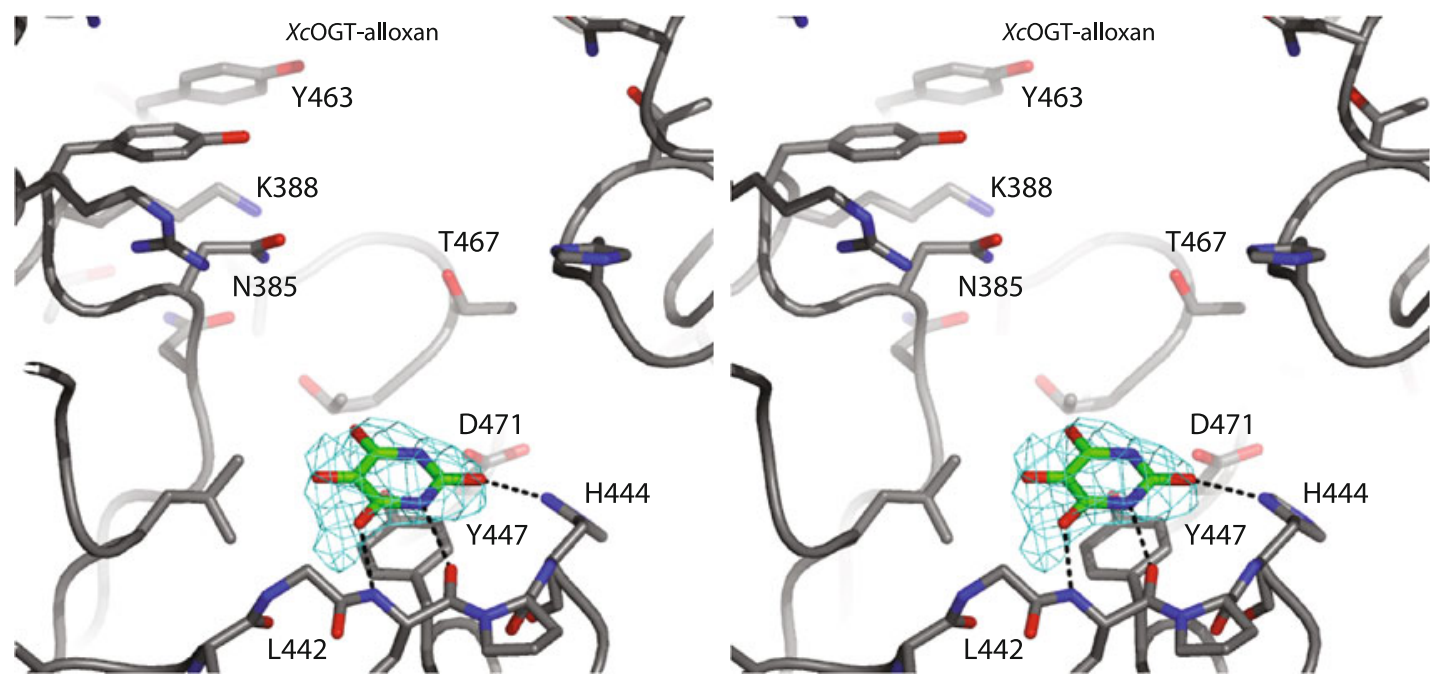
Fig. 2 X-ray crystallographic determination of inhibitor binding modes. a Stereo figure of $X c$ OGT in complex with UDP-S-GlcNAc and superposition of the previously described $X c$ OGT-UDP-CGlcNAc complex [PDB entry 2JLB (Clarke et al. 2008)]. XcOGT active site residues are shown in sticks with grey carbon, red oxygen, blue nitrogen atoms. UDP-S-GlcNAc and UDP-C-GlcNAc are shown with green and purple carbon, respectively. Hydrogen bonds for the $X c$ OGT-UDP-S-GlcNAc complex are indicated by black dashed lines. Unbiased $\left|F_{\mathrm{o}}\right|-\left|F_{\mathrm{c}}\right|, \phi_{\text {calc }}$ electron density map $(2.75 \sigma)$ is shown as cyan chickenwire. b Stereo figure of XcOGT in complex with $C$-UDP compared to the UDP complex [PDB entry 2VSN (MartinezFleites et al. 2008)]. XcOGT active site residues are shown in sticks with grey carbon, red oxygen, blue nitrogen atoms (transparent sticks for $\mathrm{XcOGT-UDP),} \mathrm{ligands} \mathrm{shown} \mathrm{in} \mathrm{green} \mathrm{carbon} \mathrm{atoms.} \mathrm{Active} \mathrm{site}$ residues involved in hydrogen bonds are labelled. Hydrogen bonds are indicated by black dashed lines. Unbiased $\left|F_{\mathrm{o}}\right|-\left|F_{\mathrm{c}}\right|, \phi_{\text {calc }}$ electron density map $(2.25 \sigma)$ is shown as cyan chickenwire. c Stereo figure of $X c$ OGT in complex with alloxan. $X c$ OGT active site are shown in sticks with green carbon, red oxygen, blue nitrogen atoms in the active site of XcOGT (sticks with grey carbon atoms). Hydrogen bonds are indicated by black dashed lines. Unbiased $\left|\mathrm{F}_{\mathrm{o}}\right|-\left|\mathrm{F}_{\mathrm{c}}\right|, \phi_{\text {calc }}$ electron density map $(2.25 \sigma)$ is shown as cyan chickenwire. Black dashed lines showing hydrogen bonds for XcOGT-alloxan complex

to UDP (Fig. 2b). The uracil ring of $C$-UDP interacts with the $X c$ OGT protein via the same three hydrogen bonds and $\pi-\pi$ stacking interactions as observed for the UDP-S-GlcNAc complex vide supra (Fig. 2a, b). The key hydrogen bond of the ribose with Asp471 is also conserved. In agreement with this, SPR measurements with the $X_{c}$ OGT-D471A mutant revealed that neither UDP nor $C$-UDP bind to the mutant enzyme (Table 2). Interestingly, however, the $\alpha, \beta$-phosphonates are shifted (maximum atomic shift $=1.4 \AA$ ) compared to the previously published XcOGT-UDP complex (MartinezFleites et al. 2008). While Asn385 and Lys388 still hydrogen bond the phosphonates (albeit with swapped interactors compared to the $X c$ OGT-UDP-S-GlcNAc complex; Fig. 2a), no hydrogen bonds between the $\beta$-phosphonate and Thr468/Lys388 are present (4.5 and $3.7 \AA$, respectively) as a result of the methylene-induced positional shift of the $\beta$-phosphonate. However, an additional hydrogen bond is introduced between Tyr468 and the $\beta$-phosphonate. This could explain the lower inhibition constant of $C$-UDP in comparison to UDP (Table 1).

Alloxan mimics the uracil binding mode in the $\mathrm{XcOGT}$ structure

The first hOGT inhibitor described was the uracil derivative alloxan (Konrad et al. 2002; Fig. 1a). It was proposed that alloxan inhibits hOGT through covalent modification of cysteine residues (Konrad et al. 2002). In our assay, alloxan is a low micromolar inhibitor of hOGT $\left(\mathrm{IC}_{50}\right.$ of $\left.18 \mu \mathrm{M}\right)$ compared to the previously reported $\mathrm{IC}_{50}$ of $100 \mu \mathrm{M}$ (Konrad et al. 2002). It is revealing to express the average contribution per atom to the $\Delta \mathrm{G}$ of binding [the so-called binding efficiency index (BEI) (Abad-Zapatero and Metz 2005)] for the hOGT inhibitors (Table 1). Interestingly, even though the small compound alloxan is a weaker inhibitor of hOGT than UDP and $C$-UDP, however, in absolute terms, in terms of ligand efficiency alloxan is a more efficient binder (BEI of 34) than UDP and $C$-UDP (BEI of 15 and 13, respectively). Thus, these data indicate that alloxan, although chemically unstable, may be a very efficient fragment to probe the hOGT uracil-binding site, perhaps as a moiety or as part of a large inhibitor molecule. To allow such inhibitors to be developed, we attempted to obtain an XcOGT-alloxan complex. XcOGT crystals were soaked with alloxan and data were collected to $2.55 \AA$ (Table 3). Well-defined electron density for alloxan is located in the uracil pocket, with the compound mimicking the previously described $\mathrm{XcOGT}$-uracil interactions (Fig. 2c). The $\mathrm{C} 2$ and C4/C6-carbonyl groups (numbering system according to Fig. 1a) accept hydrogen bonds from the side chain nitrogen of His444 and the backbone nitrogen atom of Leu442, respectively (Fig. 2c). A third hydrogen bond is formed between the alloxan N1/N3 and the backbone carbonyl of Leu442. $\pi-\pi$ stacking interactions are observed with the aromatic side chain of Tyr447 (His901 in hOGT). Previous work has described an 'active site lid' (Clarke et al. 2008) that controls access to the donor binding site-this loop is observed to be in the 'closed' conformation in the alloxan complex. There is no evidence to support the recent hypothesis that alloxan covalently modifies active site cysteine residues (Konrad et al. 2002). Unexpectedly, SPR experiments carried out with $X c \mathrm{OGT}$ revealed a weak binding constant of alloxan to $X c$ OGT $\left(K_{\mathrm{d}}>1 \mathrm{mM}\right)$. It is possible that alloxan degraded to alloxanic acid over the course of the experiment, but it should also be noted that the two substrate analogues reported here showed significantly weaker binding to $X c$ OGT than their observed inhibition of hOGT.

\section{Concluding remarks}

In the search for novel hOGT inhibitors, we have focussed our work on the synthesis and evaluation of novel hOGT substrate and product analogues (Fig. 1). The inhibitory potency of these compounds revealed that they are all sub-millimolar inhibitors of hOGT (Table 1). Structural data obtained from UDP-S-GlcNAc soaking experiments with $\mathrm{XcOGT}$ crystals revealed a competitive binding mode, yet different from the previously published UDP- $C$-GlcNAc complex (Clarke et al. 2008). The sugar 
moiety projects above the diphosphate group mimic positioning the thioglycosidic bond within hydrogen bonding distance of Asn385, which might play a role in catalysis [mutation of the equivalent Gln839 in hOGT generates an inactive species (Clarke et al. 2008; Martinez-Fleites et al. 2008)]. This could be similar to the role of Gln189 in LgtC, a retaining galactosyltransferase from Neisseria meningitidis (Tvaroska 2004). On the basis of structural, biochemical and molecular modelling, Gln189 in LgtC was predicted to be involved in hydrogen bond formation with the donor and the acceptor in the transition state (Tvaroska 2004). However, the identity of the catalytic base in hOGT remains to be firmly established.

To further investigate the reduced inhibitory effects of the potent UDP analogue, we determined the crystallographic complex of $X c \mathrm{OGT}-C$-UDP. A hydrogen bond network, similar to the previously reported $X c$ OGT-UDP complex, was observed, however, conformational changes for the $\beta$-phosphonate result in elimination of two hydrogen bonds which could explain the lower inhibition constant of $C$-UDP in comparison to UDP (Table 1). Structural and kinetic studies with alloxan, an unspecific hOGT inhibitor, have shown that this small molecule is an efficient fragment to inhibit hOGT. Chemical modifications of this compound (i.e. of the C5/C6-carbonyl groups) can be explored with the help of the binding mode revealed by the structural data presented here.

The novel substrate/product analogue hOGT inhibitors were also tested in cell-based assays, but failed to induce an observable decrease in global $O$-GlcNAcylation levels. Despite $C$-UDP being a potent hOGT inhibitor, this nucleotide analogue is a hydrophilic and negatively charged compound that might not be cell permeable. Thus, it remains to be explored whether modified (e.g. esterified) derivatives of $C$-UDP would be more cell permeable. Finally, it should be noted that all compounds considered in this study may be equally potent inhibitors of other glycosyltransferases using UDP-GlcNAc as the donor (e.g. in N-linked glycosylation), or enzymes involved in sugar nucleotide biosynthesis. It is anticipated that the structural data for the compounds reported here could aid the rational design of more potent and selective substrate/product analogue OGT inhibitors.

Acknowledgments We thank the European Synchrotron Radiation Facility, Grenoble, for the time at beam line BM14 and ID14-1. This work was supported by a Wellcome Trust Senior Fellowship and a Lister Institute for Preventive Medicine Research Prize. HCD is supported by the College of Life Sciences Alumni Studentship. The coordinates and structure factors have been deposited with the PDB (PDB entry 2xgm, 2xgs, 2xgo).

Open Access This article is distributed under the terms of the Creative Commons Attribution Noncommercial License which permits any noncommercial use, distribution, and reproduction in any medium, provided the original author(s) and source are credited.

\section{References}

Abad-Zapatero C, Metz JT (2005) Ligand efficiency indices as guideposts for drug discovery. Drug Discov Today 10(7):464-469

Banerjee S, Robbins PW, Samuelson J (2009) Molecular characterization of nucleocytosolic $O$-GlcNAc transferases of Giardia lamblia and Cryptosporidium parvum. Glycobiology 19(4):331-336

Bialy L, Waldmann H (2004) Total synthesis and biological evaluation of the protein phosphatase $2 \mathrm{~A}$ inhibitor cytostatin and analogues. Chemistry 10(11):2759-2780

Blair D, Borodkin V, Gray L, van Aalten D (manuscript submitted)

Caldwell SA, Jackson SR, Shahriari KS, Lynch TP, Sethi G, Walker S, Vosseller K, Reginato MJ (2010) Nutrient sensor it O-GlcNAc transferase regulates breast cancer tumorigenesis through targeting of the oncogenic transcription factor FoxM1. Oncogene 29:2831-2842

Chang R, Vo T, Finney N (2006) Synthesis of the C1-phosphonate analog of UDP-GlcNAc. Carbohydr Res 341:1998-2004

Chou TY, Hart GW (2001) $O$-linked $N$-acetylglucosamine and cancer: messages from the glycosylation of c-Myc. Adv Exp Med Biol 491:413-418

Clarke AJ, Hurtado-Guerrero R, Pathak S, Schuttelkopf AW, Borodkin V, Shepherd SM, Ibrahim AFM, van Aalten DMF (2008) Structural insights into mechanism and specificity of $O$-GlcNAc transferase. EMBO J 27(20):2780-2788

Cohen SB, Halcomb RL (2000) Synthesis and characterization of an anomeric sulfur analogue of CMP-sialic acid. J Org Chem 65(19):6145-6152

Comtesse N, Maldener E, Meese E (2001) Identification of a nuclear variant of MGEA5, a cytoplasmic hyaluronidase and a $\beta-N$ acetylglucosaminidase. Biochem Biophys Res Commun 283(3):634-640

Copeland RJ, Bullen Jr JW, Hart GW (2008) Crosstalk between glconacylation and phosphorylation: roles in insulin resistance and glucose toxicity. Am J Physiol Endocrinol Metab 295:17-28

Coutinho P, Deleury E, Davies G, Henrissat B (2003) An evolving hierarchical family classification for glycosyltransferases. J Mol Biol 328:307-317

Dennis RJ, Taylor EJ, Macauley MS, Stubbs KA, Turkenburg JP, Hart SJ, Black GN, Vocadlo DJ, Davies GJ (2006) Structure and mechanism of a bacterial $\beta$-glucosaminidase having $O$-GlcNAcase activity. Nat Struct Mol Biol 13:365-371

Dias W, Hart G (2007) $O$-GlcNAc modification in diabetes and Alzheimer's disease. Mol Biosyst 3:766-772

Donadio AC, Lobo C, Tosina M, de la Rosa V, Martin-Rufian M, Campos-Sandoval JA, Mates JM, Marquez J, Alonso FJ, Segura JA (2008) Antisense glutaminase inhibition modifies the $O$-GlcNAc pattern and flux through the hexosamine pathway in breast cancer cells. J Cell Biochem 103(3):800-811

Dong DLY, Hart GW (1994) Purification and characterization of an $O$-GlcNAc selective $N$-acetyl- $\beta$-D-glucosaminidase from rat spleen cytosol. J Biol Chem 269:19321-19330

Dorfmueller HC, Borodkin VS, Schimpl M, Shepherd SM, Shpiro NA, van Aalten DMF (2006) GlcNAcstatin: a picomolar, selective $O$-GlcNAcase inhibitor that modulates intracellular $O$-GlcNAcylation levels. J Am Chem Soc 128:16484-16485

Dorfmueller HC, Borodkin VS, Schimpl M, van Aalten DMF (2009) GlcNAcstatins are nanomolar inhibitors of human $O$-GlcNAcase 
inducing cellular hyper-O-GlcNAcylation. Biochem J 420(2): 221-227

Emsley P, Cowtan K (2004) Coot: model-building tools for molecular graphics. Acta Crystallogr Sect F Struct Biol Cryst Commun D60:2126-2132

Ficko-Blean E, Gregg KJ, Adams JJ, Hehemann J-H, Czjzek M, Smith SP, Boraston AB (2009) Portrait of an enzyme, a complete structural analysis of a multimodular beta- $N$-acetylglucosaminidase from Clostridium perfringens. J Biol Chem 284(15): 9876-9884

Forsythe ME, Love DC, Lazarus BD, Kim EJ, Prinz WA, Ashwell G, Krause MW, Hanover JA (2006) Caenorhabditis elegans ortholog of a diabetes susceptibility locus: OGA-1 (O-GlcNAcase) knockout impacts $O$-GlcNAc cycling, metabolism, and dauer. Proc Natl Acad Sci USA 103:11952-11957

Gao Y, Wells L, Comer FI, Parker GJ, Hart GW (2001) Dynamic $O$-glycosylation of nuclear and cytosolic proteins-cloning and characterization of a neutral, cytosolic $\beta$ - $N$-acetylglucosaminidase from human brain. J Biol Chem 276:9838-9845

Griffith LS, Schmitz B (1995) $O$-linked $N$-acetylglucosamine is upregulated in Alzheimer brains. Biochem Biophys Res Commun 213(2):424-431

Gross BJ, Kraybill BC, Walker S (2005) Discovery of $O$-GlcNAc transferase inhibitors. J Am Chem Soc 127:14588-14589

Hajduch J, Nam G, Kim E, Fraehlich R, Hanover J, Kirk K (2008) A convenient synthesis of the C-1-phosphonate analogue of UDPGlcNAc and its evaluation as an inhibitor of $O$-linked GlcNAc transferase (OGT). Carbohydr Res 343:189-195

Haltiwanger R, Blomberg M, Hart G (1992) Glycosylation of nuclear and cytoplasmic proteins. Purification and characterization of a uridine diphospho- $N$-acetylglucosamine:polypeptide $\beta$ - $N$-acetylglucosaminyltransferase. J Biol Chem 267:9005-9013

Haltiwanger RS, Grove K, Philipsberg GA (1998) Modulation of $\mathrm{O}$-linked $N$-acetylglucosamine levels on nuclear and cytoplasmic proteins in vivo using the peptide $O$-GlcNAc- $\beta$ - $N$-acetylglucosaminidase inhibitor O-(2-acetamido-2-deoxy-D-glucopyranosylidene)amino- $N$-phenylcarbamate. J Biol Chem 273:3611-3617

Hanover JA, Krause MW, Love DC (2009) The hexosamine signaling pathway: $O$-GlcNAc cycling in feast or famine. Biochim Biophys Acta 1800:80-95

Hart GW, Housley MP, Slawson C (2007) Cycling of $O$-linked $\beta$ - $N$ acetylglucosamine on nucleocytoplasmic proteins. Nature 446:1017-1022

Hurtado-Guerrero R, Dorfmueller HC, van Aalten DMF (2008) Molecular mechanisms of $O$-GlcNAcylation. Curr Opin Struct Biol 18(5):551-557

Jacobsen SE, Binkowski KA, Olszewski NE (1996) SPINDLY, a tetratricopeptide repeat protein involved in gibberellin signal transduction in Arabidopsis. Proc Natl Acad Sci USA 93(17):9292-9296

Kang E-S, Han D, Park J, Kwak TK, Oh M-A, Lee S-A, Choi S, Park ZY, Kim Y, Lee JW (2008) $O$-GlcNAc modulation at Akt1 Ser473 correlates with apoptosis of murine pancreatic beta cells. Exp Cell Res 314(11-12):2238-2248

Kelly WG, Hart GW (1989) Glycosylation of chromosomal proteins: localization of $O$-linked $\mathrm{N}$-acetylglucosamine in Drosophila chromatin. Cell 57(2):243-251

Knapp S, Myers D (2001) Alpha-GlcNAc thioconjugates. J Org Chem 66:3636-3638

Konrad RJ, Zhang FX, Hale JE, Knierman MD, Becker GW, Kudlow JE (2002) Alloxan is an inhibitor of the enzyme $O$-linked $\mathrm{N}$-acetylglucosamine transferase. Biochem Biophys Res Commun 293:207-212

Kreppel L, Blomberg M, Hart G (1997) Dynamic glycosylation of nuclear and cytosolic proteins. Cloning and characterization of a unique O-GlcNAc transferase with multiple tetratricopeptide repeats. J Biol Chem 272:9308-9315

Laughlin ST, Bertozzi CR (2009) In vivo imaging of caenorhabditis elegans glycans. ACS Chem Biol 4(12):1068-1072

Leatherbarrow RJ (2001) GraFit. Version 5. Erithacus Software Ltd, Horley

Lenzen S, Munday R (1991) Thiol-group reactivity, hydrophilicity and stability of alloxan, its reduction products and its $\mathrm{N}$-methyl derivatives and a comparison with ninhydrin. Biochem Pharmacol 42(7):1385-1391

Liu K, Paterson AJ, Chin E, Kudlow JE (2000) Glucose stimulates protein modification by $O$-linked GlcNAc in pancreatic $\beta$-cells: linkage of $O$-linked GlcNAc to $\beta$-cell death. Proc Natl Acad Sci USA 97:2820-2825

Liu K, Paterson AJ, Konrad RJ, Parlow AF, Jimi S, Roh M, Chin EJ, Kudlow JE (2002) Streptozotocin, an $O$-GlcNAcase inhibitor, blunts insulin and growth hormone secretion. Mol Cell Endocrinol 194(1-2):135-146

Liu K, Paterson A, Zhang F, McAndrew J, Fukuchi K, Wyss J, Peng $\mathrm{L}, \mathrm{Hu} \mathrm{Y}$, Kudlow J (2004) Accumulation of protein $O$-GlcNAc modification inhibits proteasomes in the brain and coincides with neuronal apoptosis in brain areas with high $O$-GlcNAc metabolism. J Neurochem 89:1044-1055

Liu J, Yu Y, Fan YZ, Chang H, Liu HM, Cui Y, Chen Q, Wang R (2005) Cardiovascular effects of endomorphins in alloxaninduced diabetic rats. Peptides 26(4):607-614

Liu J, Pang Y, Chang T, Bounelis P, Chatham JC, Marchase RB (2006) Increased hexosamine biosynthesis and protein $O$-GlcNAc levels associated with myocardial protection against calcium paradox and ischemia. J Mol Cell Cardiol 40(2): 303-312

Liu J, Marchase RB, Chatham JC (2007) Glutamine-induced protection of isolated rat heart from ischemia/reperfusion injury is mediated via the hexosamine biosynthesis pathway and increased protein $O$-GlcNAc levels. J Mol Cell Cardiol 42(1):177-185

Love DC, Hanover JA (2005) The hexosamine signaling pathway: deciphering the "O-GlcNAc code". Sci STKE 312:1-14

Lubas W, Frank D, Krause M, Hanover J (1997) $O$-Linked GlcNAc transferase is a conserved nucleocytoplasmic protein containing tetratricopeptide repeats. J Biol Chem 272:9316-9324

Macauley MS, Whitworth GE, Debowski AW, Chin D, Vocadlo DJ (2005) $O$-GlcNAcase uses substrate-assisted catalysis-kinetic analysis and development of highly selective mechanisminspired inhibitors. J Biol Chem 280:25313-25322

Marlow A, Kiessling L (2001) Improved chemical synthesis of UDPgalactofuranose. Org Lett 3:2517-2519

Martinez-Fleites C, Macauley M, He Y, Shen D, Vocadlo D, Davies $\mathrm{G}$ (2008) Structure of an $O$-GlcNAc transferase homolog provides insight into intracellular glycosylation. Nat Struct Mol Biol 15:764-765

McClain DA, Lubas WA, Cooksey RC, Hazel M, Parker GJ, Love DC, Hanover JA (2002) Altered glycan-dependent signaling induces insulin resistance and hyperleptinemia. Proc Natl Acad Sci USA 99:10695-10699

Murshudov GN, Vagin AA, Dodson EJ (1997) Refinement of macromolecular structures by the maximum-likelihood method. Acta Crystallogr Sect F Struct Biol Cryst Commun D53:240-255

Noach N, Segev Y, Levi I, Segal S, Priel E (2007) Modification of topoisomerase I activity by glucose and by $O$-GlcNAcylation of the enzyme protein. Glycobiology 17(12):1357-1364

Pape T, Schneider TR (2004) HKL2MAP: a graphical user interface for macromolecular phasing with SHELX programs. J Appl Crystallogr 37:843-844 
Rao FV, Dorfmueller HC, Villa F, Allwood M, Eggleston IM, van Aalten DMF (2006) Structural insights into the mechanism and inhibition of eukaryotic $O$-GlcNAc hydrolysis. EMBO J 25:1569-1578

Schuettelkopf AW, van Aalten DMF (2004) PRODRG: a tool for high-throughput crystallography of protein-ligand complexes. Acta Cryst D60:1355-1363

Shafi R, Lyer SPN, Ellies LG, O'Donnell N, Marek KW, Chui D, Hart GW, Marth JD (2000) The $O$-GlcNAc transferase gene resides on the $\mathrm{x}$ chromosome and is essential for embryonic stem cell viability and mouse ontogeny. Proc Natl Acad Sci USA 97:5735-5739

Stubbs KA, Zhang N, Vocadlo DJ (2006) A divergent synthesis of 2-acyl derivatives of PUGNAc yields selective inhibitors of $O$-GlcNAcase. Org Biomol Chem 4:839-845

Torres CR, Hart GW (1984) Topography and polypeptide distribution of terminal $\mathrm{N}$-acetylglucosamine residues on the surfaces of intact lymphocytes - evidence for $O$-linked GlcNAc. J Biol Chem 259:3308-3317

Tvaroska I (2004) Molecular modeling insights into the catalytic mechanism of the retaining galactosyltransferase LgtC. Carbohydr Res 339(5):1007-1014
Wells L, Hart GW (2003) $O$-GlcNAc turns twenty: functional implications for post-translational modification of nuclear and cytosolic proteins with a sugar. FEBS Lett 546:154-158

Yang W, Kim J, Nam H, Ju J, Kim H, Kim Y, Cho J (2006) Modification of p53 with $O$-linked $\mathrm{N}$-acetylglucosamine regulates p53 activity and stability. Nat Cell Biol 8:1074-1083

Yao P, Coleman P (1998) Reduction of $O$-linked $N$-acetylglucosamine-modified assembly protein-3 in Alzheimer's disease. J Neurosci 18(7):2399-2411

Yuzwa S, Macauley M, Heinonen J, Shan X, Dennis R, He Y, Whitworth G, Stubbs K, McEachern E, Davies G, Vocadlo D (2008) A potent mechanism-inspired $O$-GlcNAcase inhibitor that blocks phosphorylation of tau in vivo. Nat Chem Biol 4:483-490

Zachara NE, Hart GW (2004) $O$-GlcNAc modification: a nutritional sensor that modulates proteasome function. Trends Cell Biol $14: 218-221$

Zachara NE, Cheung WD, Hart GW (2004) Nucleocytoplasmic glycosylation, $O$-GlcNAc: identification and site mapping. Methods Mol Biol 284:175-194 